\title{
Crescimento inicial de mudas pré-brotadas de cana-de-açúcar em duas modalidades de aplicação de herbicidas
}

\author{
Initial growth of sugarcane pre-sprouted seedlings in two types of \\ application of herbicides
}

\begin{abstract}
Ana Ligia Giraldeli ${ }^{1 *}$, André Felipe Moreira Silva ${ }^{1}$, Felipe Carrara de Brito ${ }^{1}$, Lucas da Silva Araújo ${ }^{1}$, Ana Carolina Viviani Pagenotto ${ }^{1}$, Julia Pereira de Moraes ${ }^{1}$, Ricardo Victoria Filho ${ }^{1}$
\end{abstract}

Resumo - A espécie Cyperus rotundus está entre as plantas daninhas mais difíceis de controlar, podendo causar elevados prejuízos na cultura da cana-de-açúcar. As práticas adotadas garantem os valores de produtividade, dentre elas, está o manejo de plantas daninhas. O objetivo deste trabalho foi avaliar o crescimento inicial de mudas pré-brotadas de cana-de-açúcar submetidas à aplicação de herbicidas em pré ou pós-plantio. Foram conduzidos dois experimentos (pré e pós-plantio) em casa-de-vegetação, em delineamento inteiramente casualizado, com quatro repetições. Os tratamentos correspondem aos herbicidas aplicados em três doses em pré-plantio: sulfentrazone (400, 800 e 1.600 g i.a. ha $\left.{ }^{-1}\right)$, diclosulam $\left(96,6 ; 193,17\right.$ e 386,34 g i.a. ha $\left.{ }^{-1}\right)$, imazapic $\left(66,5,133\right.$ e $266 \mathrm{~g}$ i.a. ha $\left.{ }^{-1}\right)$ e imazapyr $\left(250,500\right.$ e $1.000 \mathrm{~g}$ e.a. ha $\left.{ }^{-1}\right)$ e pós-plantio: ethoxysulfuron $(67,5,135$ e 270 g i.a. ha-1 $)$, halosulfuron $\left(56,25,112,5\right.$ e 225 g i.a. ha $\left.{ }^{-1}\right), 2,4-\mathrm{D}(670,1.340$ e 2.680 g e.a. ha-1 $)$ e MSMA $\left(987,5,1975\right.$ e 3.950 g i.a. ha-1 ${ }^{-1}$. Além de duas testemunhas sem aplicação de herbicidas. Foram avaliados os sintomas de injúrias, altura, diâmetro, número de folhas, número de perfilhos, teor de clorofila, área foliar, matéria seca da parte aérea e raiz. Os herbicidas em pós-plantio foram considerados seletivos, uma vez que os sintomas de injúrias foram baixos e os outros parâmetros avaliados não foram diferentes da testemunha. Para as aplicações em pré-plantio foram observados sintomas de injúrias até os 60 dias após a aplicação (DAA) para sulfentrazone.

Palavras-chave: controle químico, Saccharum officinarum, sintomas de injúria

Abstract - The specie Cyperus rotundus is among the weeds most difficult to control and can cause high losses in the sugarcane crop. The practices adopted in the culture guarantee the values of yield, among them, is the weed management. The objective of this work was to evaluate the initial growth of sugarcane pre-sprouted seedlings submitted to herbicide application before or after planting. Two experiments (pre and post-planting) were conducted in greenhouse, in a completely randomized design, with four replications. The treatments corresponded to the herbicides applied in three pre-planting doses: sulfentrazone $\left(400,800\right.$ and $1,600 \mathrm{~g}$ a.i. ha $\left.{ }^{-1}\right)$, diclosulam $\left(96.6,193.17\right.$ and $386.34 \mathrm{~g}$ a.i. ha $\left.\mathrm{h}^{-1}\right)$, imazapic $\left(66.5,133\right.$ and $266 \mathrm{~g}$ a.i. ha $\left.{ }^{-1}\right)$ and imazapyr $\left(250,500\right.$ and $1,000 \mathrm{~g}$ e.a. ha $\left.{ }^{-1}\right)$ and post-planting: halosulfuron $\left(56.25,112.5\right.$ and $225 \mathrm{~g}$ a.i. ha $\left.{ }^{-1}\right)$, ethoxysulfuron (67.5, 135 and $270 \mathrm{~g}$ a.i. ha $\left.{ }^{-1}\right), 2,4-\mathrm{D}$ $\left(670,1,340\right.$ and 2,680 g a.e. ha $\left.^{-1}\right)$ and MSMA $\left(987.5,1,975\right.$ and 3,950 $\mathrm{g}$ a.i. ha $\left.{ }^{-1}\right)$. In addition to two controls without herbicide application. The crop injury, height, diameter, number of leaves, number

Recebido: Agosto 17, 2018. Aceito: Novembro 24, 2018.

${ }^{1}$ Escola Superior de Agricultura "Luiz de Queiroz" - ESALQ, Universidade de São Paulo - USP, Avenida Pádua Dias, 11, CEP 13418-900, Piracicaba, SP, Brasil. E-mail: analigia_giraldeli@hotmail.com; afmoreirasilva@hotmail.com; britofelipe@hotmail.com; 1.s.araujo@usp.br; ana.pagenotto@gmail.com; juliapmoraes@usp.br; rvictori@usp.br 
of tillers, chlorophyll content, leaf area, dry mass of shoot and root were evaluated. Post-planting treatments were considered selective, since the crop injury were low, and the other parameters evaluated were not different from the control. For pre-planting applications, crop injury were observed up to 60 days after application (DAA) for sulfentrazone.

Keywords: chemical control, Saccharum officinarum, crop injury

\section{Introdução}

O Brasil é o maior produtor de cana-de-açúcar do mundo, produzindo além do açúcar e do etanol, energia elétrica. O país apresenta condições favoráveis a produção do cultivo uma vez que possui grandes áreas e condições edafoclimáticas adequadas para o cultivo. Aárea com cana-de-açúcar na safra 2016/2017 chegou a 9.049,2 mil ha, com produtividade de $72.623 \mathrm{~kg} \mathrm{ha}^{-1}$, e produção de 657.184 mil toneladas (CONAB, 2017).

Para garantia de produtividade da cana-de-açúcar uma das etapas de grande importância, com maiores custos da produção da cultura, está o plantio. O gasto com mudas no sistema de plantio manual fica em torno de 8 a $12 \mathrm{tha}^{-1}$, chegando a utilizar até 11 a $14 \mathrm{t} \mathrm{ha}^{-1}$ para evitar falhas no plantio (15 a 21 gemas $\mathrm{m}^{-1}$ ). Com o sistema de plantio mecanizado, este número aumentou ultrapassando até $20 \mathrm{tha}^{-1}$, o que significa em torno de 24 a 60 gemas $\mathrm{m}^{-1}$, havendo uma redução de colmos que vão para a indústria (Landell et al., 2012).

O uso do sistema de MPB's vem de encontro a um plantio economicamente viável, uma vez que possui uma alta taxa de multiplicação nos viveiros. Além de áreas de viveiros primários e secundários, a tecnologia vem sendo utilizada para o replantio de falhas em talhões plantados pelo método convencional e para replantio de áreas com cana soca (Xavier et al., 2014).

Nesse contexto, surge um novo desafio relacionado ao manejo de plantas daninhas em MPB's, já que agora as mudas chegam ao campo com a parte aérea formada, com mais vigor e com sistema radicular desenvolvido e próximo a superfície do solo, o que pode gerar problemas relacionados a seletividade de herbicidas (Silva et al., 2018). Segundo Dias et al. (2017) a localização espacial do herbicida em relação a planta é responsável pela seletividade do produto a cultura, conhecida por seletividade de posicionamento.

Algumas plantas daninhas de difícil controle ainda estão entre as principais espécies encontradas nos canaviais, como: C. rotundus e Cynodon dactylon. Kuva et al. (2008) observaram a presença de $C$. rotundus com elevada importância relativa (IR) $(438,7 \%)$ em lavouras de cana-de-açúcar. Em outro trabalho, Kuva et al. (2007) também verificaram a espécie como tendo a maior IR de 1.299, aos 120 dias após o corte da cana-de-açúcar. A redução da produtividade quando a cultura conviveu com plantas daninhas durante todo o ciclo foi de $20 \%$, reduzindo de $159 \mathrm{t} \mathrm{ha}^{-1}$ para $128 \mathrm{t} \mathrm{ha}^{-1}$, em comunidade de infestantes na qual a espécie C. rotundus era superior a $50 \%$ (Kuva et al., 2000).

Dentre os herbicidas utilizados para o manejo de C. rotundus estão o sulfentrazone, diclosulam, imazapic, imazapyr, halosulfuron, ethoxysulfuron, 2,4-D e MSMA (Rodrigues e Almeida, 2011). Estes, podem ser empregados em pré ou pós-emergência da planta daninha e da cana-de-açúcar de acordo com a modalidade recomendada.

Por ser um sistema de plantio proposto a pouco tempo, os estudos ainda são escassos (Gírio et al., 2015). Acredita-se que a seletividade de herbicidas seja diferente de acordo com a tolerância de cada variedade de cana-de-açúcar. Deste modo, mais pesquisas são necessárias para a compreensão da seletividade de herbicidas.

Com isso, o objetivo deste trabalho foi avaliar o crescimento inicial de mudas pré-brotadas de 
cana-de-açúcar (MPB's) quando submetidas à aplicação de herbicidas em pré ou pós-plantio.

\section{Material e métodos}

O experimento foi realizado com a variedade RB985476, em casa-de-vegetação, localizada nas coordenadas geográficas: $22^{\circ} 42^{\prime} 31,2$ ” S e $47^{\circ} 37^{\prime} 44,5^{\prime}$ ' W, altitude de $547 \mathrm{~m}$. A irrigação foi mantida simulando o mês de outubro, com média de três mm por dia (média dos últimos dez anos da região do estudo).

A variedade RB985476 foi lançada no ano de 2015 e apresenta elevado potencial para plantio. Apresenta alta produtividade, elevado teor de sacarose no meio da safra, elevada sanidade (resistente a carvão, ferrugem marrom e alaranjada, escaldadura e mosaico), além de possuir ótimo perfilhamento em cana planta e cana soca (RIDESA, 2015).

Realizou-se dois experimentos, um em pré-plantio e outro em pós-plantio. Em ambos o delineamento utilizado foi o inteiramente casualizado, com quatro repetições e unidade experimental constituída por vasos plásticos de cinco litros, preenchidos com solo peneirado. A análise química do solo apresentou as seguintes características: $\mathrm{pH}$ de 4,9; $42 \mathrm{~g} \mathrm{dm}^{-3}$ de $\mathrm{MO} ; 7 \mathrm{mg} \mathrm{dm}^{-3}$ de P; 1,69 $\mathrm{mmol}_{\mathrm{c}} \mathrm{dm}^{-3}$ de K ; 48,49 mmol $_{c} \mathrm{dm}^{-3}$ de Ca; 14,65 $\mathrm{mmol}_{\mathrm{c}} \mathrm{dm}^{-3} \mathrm{de} \mathrm{Mg}$; $22 \mathrm{mmol}_{\mathrm{c}} \mathrm{dm}^{-3} \mathrm{de} \mathrm{H}+\mathrm{Al} ; 0,26 \mathrm{mmol}_{\mathrm{c}} \mathrm{dm}^{-3} \mathrm{de} \mathrm{Al}$; $64,8 \mathrm{mmol}_{\mathrm{c}} \mathrm{dm}^{-3} \mathrm{de} \mathrm{SB} ; 86,8 \mathrm{mmol}_{\mathrm{c}} \mathrm{dm}^{-3}$ de CTC; $74,6 \%$ de saturação por bases. A análise física classificou o solo como argiloso, com $205 \mathrm{~g} \mathrm{~kg}^{-1}$ de areia fina, $148 \mathrm{~g} \mathrm{~kg}^{-1}$ de areia grossa, $353 \mathrm{~g} \mathrm{~kg}^{-1}$ de areia total, $410 \mathrm{~g} \mathrm{~kg}^{-1}$ de argila e $237 \mathrm{~g} \mathrm{~kg}^{-1}$ de limo.

Os tratamentos correspondem aos herbicidas aplicados em três doses (1/2 D; D; 2D, sendo D a dose comercial) no mesmo dia do plantio das MPB's para o experimento de pré-plantio: sulfentrazone (Boral 500 SC, 400, 800 e 1.600 g i.a. ha-1 ${ }^{-1}$ SC, FMC), diclosulam $\left(\right.$ Coact $^{\circledR}, 96,6,193,17$ e 386,34 g i.a. ha-1, WG, Dow AgroSciences), imazapic (Plateau ${ }^{\circledR}$, 66,5, 133 e 266 g i.a. ha ${ }^{-1}$, WG, Basf) e imazapyr (Contain $^{\circledR}, 250,500$ e 1.000 g e.a. ha ${ }^{-1}$, SL, Basf).
Para o experimento de pós-plantio os tratamentos correspondem aos herbicidas aplicados em três doses (1/2 D; D; 2D, sendo D a dose comercial), cinco dias após o plantio da MPB's: ethoxysulfuron (Gladium ${ }^{\circledR}$, $67,5,135$ e 270 g i.a. ha' ${ }^{-1}$, WG, Bayer), halosulfuron $\left(\right.$ Sempra $^{\circledR}, 56,25,112,5$ e 225 g i.a. ha ${ }^{-1}$, WG, Arysta), 2,4-D (DMA ${ }^{\circledR} 806$ BR, 670, 1.340 e 2.680 g e.a. ha ${ }^{-1}$, SL, Dow AgroSciences) e MSMA (Volcane ${ }^{\circledR}$, 987,5, 1.975 e 3.950 g i.a. ha-1 ${ }^{-1}$ SL, DuPont). Além de duas testemunhas sem aplicação de herbicidas.

A aplicação dos tratamentos foi realizada via pulverizador costal pressurizado a $\mathrm{CO}_{2}$, equipado com barra com quatro pontas de pulverização, a uma pressão constante de $2,1 \mathrm{kgf} \mathrm{cm}^{2}$, propiciando um volume de calda de $200 \mathrm{~L} \mathrm{ha}^{-1}$, e velocidade de $1 \mathrm{~m} \mathrm{~s}^{-1}$, sendo que as pontas foram posicionadas a uma altura de $50 \mathrm{~cm}$ do alvo. As condições no momento da aplicação eram: umidade relativa de $84 \%$, velocidade do vento de $2 \mathrm{~m} \mathrm{~s}^{-1}$ e temperatura de $18,5^{\circ} \mathrm{C}$.

Foi avaliado os sintomas de injúria nas plantas aos 7, 15, 30, 45 e 60 dias após a aplicação (DAA), através de avaliações visuais em que foram atribuídas notas percentuais que variaram de 0 a $100 \%$ a cada unidade experimental (onde 0 , representa ausência de injúrias, e 100\%, morte das plantas), considerando-se neste caso sintomas significativamente visíveis nas plantas, de acordo com seu desenvolvimento (Velini et al., 1995).

Aos 30 e 60 DAA foram avaliados a altura com auxílio de régua graduada, medindo-se o comprimento do perfilho principal da superfície do solo até a última folha desenvolvida, diâmetro do colmo a cinco $\mathrm{cm}$ do solo com paquímetro, número de folhas completamente expandidas e número de perfilhos. O teor de clorofila foi mensurado com o aparelho ClorofiLOG ${ }^{\circledR}$ CFL 1030, na folha +1 , sendo quantificadas a clorofila a, b e total, com a unidade expressa como índice de clorofila falker (ICF) de forma adimensional (Barbieri Junior et al., 2012).

Na última avaliação (60 DAA), foi realizada além das variáveis anteriores, a área foliar com aparelho LiCor, LI 3000 a do colmo principal e dos 
perfilhos. Nesta última avaliação as partes aéreas das plantas de cana-de-açúcar foram cortadas rente à superfície do solo e separadas das raízes, acondicionadas em sacos de papel devidamente identificados e submetidas a secagem em estufa com circulação forçada de ar com temperatura de $65^{\circ} \mathrm{C}$ e, depois de secos, pesados em balança analítica de precisão.

Os dados obtidos foram submetidos à análise de variância pelo teste F, e quando significativos, as médias dos tratamentos foram comparadas pelo teste de Tukey a 5\% de probabilidade. Para as avaliações de injúrias e número de perfilhos foi realizada a transformação dos dados $(X+1)^{\wedge} 0,5$ (Pimentel-Gomes e Garcia, 2002).

\section{Resultados e discussão}

Em pré-plantio, foram observados sintomas de injúrias em todas as avaliações para o herbicida sulfentrazone (1.600 g i.a. ha-1 ${ }^{-1}$, com notas de $8,75 \%$ (7 DAA), 22,5\% (15 DAA), 26,5\% (30 DAA), $25,0 \%$ (45 DAA) e $20,75 \%$ (60 DAA) (Tabela 1).
A seletividade de herbicidas em cana-de-açúcar foi estudada por Durigan et al. (2004), os autores utilizaram a variedade RB806043 e testaram os herbicidas sulfentrazone ( $700 \mathrm{~g}^{\text {i.a. }} \mathrm{ha}^{-1}$ ) e imazapic (106 g i.a. ha ${ }^{-1}$ ) em pré-emergência da cultura e de C. rotundus. Os resultados observados mostraram poucos sintomas de injúrias para esses produtos, que foram classificados com notas entre 1 e 2 segundo a escala EWRC (1964) que significa ausência de sintomas (nota 1) e sintoma muito leve (nota 2). No presente trabalho, os sintomas de injúrias para o sulfentrazone foram mais elevados, chegando até á $26,5 \%$ aos 30 DAA.

Sabbag et al. (2017) observaram injúrias de sulfentrazone (700 g i.a. ha ${ }^{-1}$ ) até 60 dias após o plantio (DAP) de mudas pré-brotadas da variedade RB867515, quando aplicado o herbicida aos 3 e 10 DAP, com nota máxima de $30 \%$ aos 15 dias após o tratamento (DAT) (3 DAP). Notas elevadas de sintomas de injúrias para sulfentrazone também foram verificadas no presente trabalho, mas quando o herbicida foi

Tabela 1. Sintomas de injúria em MPB's de cana-de-açúcar, variedade RB985476, aos 7, 15, 30, 45 e 60 DAA dos tratamentos em pré-plantio.

\begin{tabular}{|c|c|c|c|c|c|c|c|c|c|c|c|}
\hline \multirow{3}{*}{$\begin{array}{l}\text { Tratamentos } \\
\text { testemunha }\end{array}$} & \multirow{3}{*}{$\begin{array}{c}\text { Doses }^{1} \\
-\end{array}$} & \multicolumn{10}{|c|}{ Notas de injúrias (\%) } \\
\hline & & \multicolumn{2}{|c|}{7 DAA* } & \multicolumn{2}{|c|}{$15 \mathrm{DAA}^{*}$} & \multicolumn{2}{|c|}{30 DAA* } & \multicolumn{2}{|c|}{$45 \mathrm{DAA}^{*}$} & \multicolumn{2}{|c|}{60 DAA* } \\
\hline & & 0,00 & $\mathrm{a}$ & 0,00 & $\mathrm{a}$ & 0,00 & $\mathrm{a}$ & 0,00 & $\mathrm{a}$ & 0,00 & $\mathrm{a}$ \\
\hline sulfentrazone & 400 & 0,00 & $\mathrm{a}$ & 0,00 & $\mathrm{a}$ & 0,00 & $\mathrm{a}$ & 0,00 & $\mathrm{a}$ & 0,00 & $\mathrm{a}$ \\
\hline sulfentrazone & 800 & 0,00 & $\mathrm{a}$ & 0,00 & $\mathrm{a}$ & 0,75 & $\mathrm{a}$ & 0,00 & $\mathrm{a}$ & 0,00 & $\mathrm{a}$ \\
\hline sulfentrazone & 1.600 & 8,75 & $b$ & 22,50 & $\mathrm{~b}$ & 26,50 & $\mathrm{~b}$ & 25,00 & $\mathrm{~b}$ & 20,75 & $\mathrm{~b}$ \\
\hline diclosulam & 96,60 & 0,00 & a & 0,00 & $\mathrm{a}$ & 5,00 & $\mathrm{a}$ & 1,50 & $\mathrm{a}$ & 3,25 & a \\
\hline diclosulam & 193,17 & 0,00 & $\mathrm{a}$ & 0,00 & $\mathrm{a}$ & 4,00 & $\mathrm{a}$ & 3,50 & $\mathrm{a}$ & 7,50 & $\mathrm{ab}$ \\
\hline diclosulam & 386,34 & 0,00 & $\mathrm{a}$ & 0,00 & $\mathrm{a}$ & 5,00 & $\mathrm{a}$ & 5,24 & $a b$ & 11,25 & $a b$ \\
\hline imazapic & 66,50 & 0,00 & $\mathrm{a}$ & 0,00 & $\mathrm{a}$ & 0,00 & $\mathrm{a}$ & 0,00 & $\mathrm{a}$ & 0,00 & $\mathrm{a}$ \\
\hline imazapic & 133 & 0,00 & $\mathrm{a}$ & 0,00 & $\mathrm{a}$ & 0,75 & $\mathrm{a}$ & 0,00 & $\mathrm{a}$ & 0,00 & $\mathrm{a}$ \\
\hline imazapic & 266 & 0,00 & $\mathrm{a}$ & 0,00 & $\mathrm{a}$ & 1,75 & $\mathrm{a}$ & 0,75 & $\mathrm{a}$ & 1,25 & $\mathrm{a}$ \\
\hline imazapyr & 250 & 0,00 & $\mathrm{a}$ & 0,00 & $\mathrm{a}$ & 1,25 & $\mathrm{a}$ & 0,00 & $\mathrm{a}$ & 2,00 & $\mathrm{a}$ \\
\hline imazapyr & 500 & 0,00 & $\mathrm{a}$ & 0,00 & $\mathrm{a}$ & 6,50 & $\mathrm{a}$ & 5,00 & $\mathrm{ab}$ & 6,25 & $a b$ \\
\hline \multirow[t]{4}{*}{ imazapyr } & 1.000 & 0,00 & $\mathrm{a}$ & 0,00 & $\mathrm{a}$ & 9,00 & $a b$ & 6,75 & $\mathrm{ab}$ & 13,00 & $a b$ \\
\hline & Média & 0,67 & & 1,73 & & 4,50 & & 3,67 & & 5,01 & \\
\hline & DMS & 12,09 & & 18,18 & & 19,56 & & 20,42 & & 16,53 & \\
\hline & C.V. $(\%)$ & 63,26 & & 75,95 & & 51,05 & & 61,57 & & 45,21 & \\
\hline
\end{tabular}

${ }^{1}$ Dose em g i.a. ha ${ }^{-1}$ ou g e.a. ha ${ }^{-1}$; ${ }^{*}$ médias seguidas por letras iguais na coluna, não diferem entre si pelo teste Tukey a 5\% de probabilidade; DMS = diferença mínima significativa; C.V. = coeficiente de variação; dados transformados $\mathrm{em}(\mathrm{X}+1)^{\wedge} 0,5$. 
aplicado em pré-plantio na dose de $1.600 \mathrm{~g}$ i.a. ha ${ }^{-1}$ e na variedade RB985476.

O herbicida sulfentrazone ( $800 \mathrm{~g}^{\text {i.a. }} \mathrm{ha}^{-1}$ ) também causou injúrias na variedade RB867515 até 45 dias após a emergência (DAE), com nota máxima de 28,3\% (15 DAE), sintomas também observados na variedade RB975201, com 53,3\% aos 30 DAE e na RB975952 com 20,0\% aos 15 DAE (Giraldeli et al., 2016). Esses resultados sugerem que as mudas pré-brotadas são mais sensíveis aos herbicidas em pré-plantio, já que até os $60 \mathrm{DAA}$ as plantas ainda não haviam se recuperado das injúrias, resultados esses não verificados quando o herbicida é aplicado em pré-emergência em sistema de plantio convencional.

A variável altura foi reduzida aos 60 DAA para os tratamentos sulfentrazone (1.600 g i.a. ha ${ }^{-1}$ ), diclosulam $\left(96,6 ; 183,17\right.$ e 386,34 g i.a. ha $\left.{ }^{-1}\right)$ e imazapyr (500 e $1.000 \mathrm{~g}$ e.a. ha-1) em relação à testemunha sem aplicação. $\mathrm{O}$ diâmetro do colmo também foi reduzido na avaliação de 60 DAA para os herbicidas diclosulam $\left(96,6\right.$ e 386,34 g i.a. ha $\left.{ }^{-1}\right)$ e imazapyr (1.000 g e.a. ha $\left.{ }^{-1}\right)$ (Tabela 2). Durigan et al. (2004) não verificaram redução na altura quando utilizado o herbicida sulfentrazone ( $700 \mathrm{~g}$ i.a. $\mathrm{ha}^{-1}$ ) e imazapic (105 g i.a ha $\left.{ }^{-1}\right)$, diferindo do encontrado no presente trabalho.

Para número de folhas, aos $30 \mathrm{DAA}$, os tratamentos com o herbicida diclosulam nas

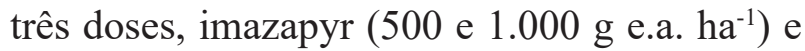
sulfentrazone $\left(1.600 \mathrm{~g}\right.$ i.a. ha $\left.^{-1}\right)$ foram estatisticamente inferiores à testemunha. Todavia, aos 60 DAA, esta diferença só foi observada para sulfentrazone (Tabela 3).

O uso de sulfentrazone ( $800 \mathrm{~g}$ i.a. ha $\left.{ }^{-1}\right)$, imazapic $\left(105\right.$ g i.a. ha $\left.{ }^{-1}\right)$ e flazasulfuron (150 g i.a. ha $\left.{ }^{-1}\right)$ em pré-emergência, e trifloxysulfuron + ametryn (1.500 g i.a. ha $\left.{ }^{-1}\right)$, halosulfuron (105 g i.a. ha $\left.{ }^{-1}\right)$ e flazasulfuron ( $150 \mathrm{~g}$ i.a. ha $\left.{ }^{-1}\right)$ em pós-emergência, na variedade SP 86042 obtiveram produtividades estatisticamente iguais em relação à testemunha capinada. Até $65 \mathrm{DAA}$, os herbicidas flazasulfuron e imazapic foram os que proporcionaram maiores notas de sintomas de injúrias, como

Tabela 2. Altura e diâmetro de MPB's de cana-de-açúcar, variedade RB985476, aos 30 e 60 DAA dos tratamentos em pré-plantio.

\begin{tabular}{|c|c|c|c|c|c|c|c|}
\hline \multirow{2}{*}{ Tratamentos } & \multirow{2}{*}{ Doses $^{1}$} & \multicolumn{3}{|c|}{ Altura (cm) } & \multicolumn{3}{|c|}{ Diâmetro (cm) } \\
\hline & & $30^{\mathrm{ns}}$ & \multicolumn{2}{|c|}{$60 \%$} & $30^{\text {ns }}$ & \multicolumn{2}{|c|}{$60 *$} \\
\hline testemunha & - & 19,00 & 34,50 & $\mathrm{a}$ & 0,75 & 1,05 & $\mathrm{a}$ \\
\hline sulfentrazone & 400 & 20,00 & 30,00 & $a b c$ & 0,63 & 0,87 & $a b$ \\
\hline sulfentrazone & 800 & 20,00 & 30,37 & $a b c$ & 0,65 & 0,81 & $a b$ \\
\hline sulfentrazone & 1.600 & 19,50 & 24,00 & bcde & 0,56 & 0,60 & $\mathrm{ab}$ \\
\hline diclosulam & 96,60 & 18,75 & 23,00 & cde & 0,53 & 0,56 & $\mathrm{~b}$ \\
\hline diclosulam & 193,17 & 18,25 & 20,37 & de & 0,62 & 0,60 & $a b$ \\
\hline diclosulam & 386,34 & 17,75 & 19,75 & $\mathrm{e}$ & 0,66 & 0,57 & $\mathrm{~b}$ \\
\hline imazapic & 66,50 & 19,50 & 32,87 & $a b$ & 0,71 & 0,88 & $a b$ \\
\hline imazapic & 133 & 18,75 & 33,50 & $a b$ & 0,70 & 0,86 & $a b$ \\
\hline imazapic & 266 & 18,25 & 29,12 & abcde & 0,58 & 0,77 & $\mathrm{ab}$ \\
\hline imazapyr & 250 & 18,00 & 29,62 & abcd & 0,67 & 0,90 & $\mathrm{ab}$ \\
\hline imazapyr & 500 & 19,50 & 22,50 & cde & 0,61 & 0,80 & $a b$ \\
\hline \multirow[t]{4}{*}{ imazapyr } & 1.000 & 18,50 & 21,50 & cde & 0,57 & 0,55 & $\mathrm{~b}$ \\
\hline & Média & 18,90 & 27,00 & & 0,63 & 0,75 & \\
\hline & DMS & 3,69 & 9,53 & & 0,24 & 0,45 & \\
\hline & C.V. $(\%)$ & 7,84 & 14,16 & & 15,60 & 23,96 & \\
\hline
\end{tabular}

${ }^{1}$ Dose em g i.a. ha ${ }^{-1}$ ou g e.a. ha ${ }^{-1} ; *^{*}$ médias seguidas por letras iguais na coluna, não diferem entre si pelo teste Tukey a $5 \%$ de probabilidade; ${ }^{\text {ns }}=$ não significativo pelo teste Tukey a $5 \%$ de probabilidade; DMS $=$ diferença mínima significativa; C.V. = coeficiente de variação. 
Tabela 3. Número de folhas e perfilhos de MPB's de cana-de-açúcar, variedade RB985476, aos 30 e 60 DAA dos tratamentos em pré-plantio.

\begin{tabular}{|c|c|c|c|c|c|c|c|}
\hline \multirow{2}{*}{ Tratamentos } & \multirow{2}{*}{ Doses $^{1}$} & \multicolumn{4}{|c|}{ Número de folhas } & \multicolumn{2}{|c|}{ Número de perfilhos } \\
\hline & & \multicolumn{2}{|c|}{$30 *$} & \multicolumn{2}{|c|}{$60 *$} & $30^{\text {ns }}$ & $60^{\text {ns }}$ \\
\hline testemunha & - & 9,75 & $\mathrm{a}$ & 8,25 & $\mathrm{a}$ & 1,50 & 2,75 \\
\hline sulfentrazone & 400 & 7,25 & $a b$ & 8,00 & $\mathrm{a}$ & 1,00 & 2,00 \\
\hline sulfentrazone & 800 & 7,75 & $a b$ & 7,50 & $\mathrm{a}$ & 1,50 & 2,50 \\
\hline sulfentrazone & 1.600 & 5,25 & $\mathrm{~b}$ & 4,25 & $\mathrm{~b}$ & 2,25 & 3,50 \\
\hline diclosulam & 96,60 & 5,00 & $\mathrm{~b}$ & 7,00 & $a b$ & 0,50 & 2,50 \\
\hline diclosulam & 193,17 & 5,75 & $\mathrm{~b}$ & 6,75 & $a b$ & 1,00 & 2,00 \\
\hline diclosulam & 386,34 & 5,50 & $\mathrm{~b}$ & 6,75 & $a b$ & 0,50 & 0,75 \\
\hline imazapic & 66,50 & 6,50 & $a b$ & 7,50 & $\mathrm{a}$ & 1,00 & 2,50 \\
\hline imazapic & 133 & 6,50 & $a b$ & 8,25 & $\mathrm{a}$ & 0,25 & 1,50 \\
\hline imazapic & 266 & 6,75 & $a b$ & 7,50 & $\mathrm{a}$ & 1,00 & 1,75 \\
\hline imazapyr & 250 & 7,50 & $a b$ & 7,75 & $\mathrm{a}$ & 1,25 & 2,75 \\
\hline imazapyr & 500 & 5,75 & $\mathrm{~b}$ & 6,25 & $a b$ & 0,00 & 1,25 \\
\hline \multirow[t]{4}{*}{ imazapyr } & 1.000 & 5,75 & $\mathrm{~b}$ & 5,75 & $a b$ & 0,00 & 0,50 \\
\hline & Média & 6,53 & & 7,03 & & 0,90 & 2,01 \\
\hline & DMS & 3,74 & & 3,16 & & 2,59 & 3,47 \\
\hline & C.V. (\%) & 22,97 & & 18,06 & & 25,93 & 22,77 \\
\hline
\end{tabular}

${ }^{1}$ Dose em g i.a. ha ${ }^{-1}$ ou g e.a. ha ${ }^{-1} ; *$ médias seguidas por letras iguais na coluna, não diferem entre si pelo teste Tukey a $5 \%$ de probabilidade; ${ }^{\text {ns }}=$ não significativo; DMS = diferença mínima significativa; C.V. = coeficiente de variação.

clorose e retardo de desenvolvimento inicial da cana-de-açúcar. Para todos os tratamentos a altura de plantas foi igual a testemunha capinada e apenas o herbicida flazasulfuron teve redução da produtividade de $11,9 \%$ em relação a testemunha (Durigan et al., 2005). Os resultados diferiram dos observados no presente trabalho, no qual as maiores notas de injúrias para imazapic foram de $1,75 \%$ (266 g i.a. ha $\left.{ }^{-1}\right)$. Quanto à altura, os resultados corroboram com o exposto, uma vez que nas mesmas doses utilizadas não foi observada redução para este parâmetro para os herbicidas sulfentrazone, imazapic e halosulfuron.

Sabbag et al. (2017) não observaram redução da altura e área foliar das variedades RB867515 e RB855156 quando utilizado sulfentrazone em pós-plantio (3 e 10 DAP), já para a RB966928 constataram redução de altura quando o herbicida foi aplicado aos 3 DAP. Fato esse, que ressalta a tolerância diferencial das variedade cana-de-açúcar e ao posicionamento dos herbicidas.

Em relação aos parâmetros clorofila a, clorofila b e clorofila total, foi verificada diferença apenas aos 60 DAA, sendo menor para os tratamentos diclosulam (193,17 e 386,34 g i.a. ha $\left.{ }^{-1}\right)$ e imazapyr (1.000 g e.a. ha-1) (Tabela 4). Esses menores valores de clorofila podem ser relacionados com os sintomas de injúrias observados nas plantas de cana-de-açúcar.

Os tratamentos sulfentrazone (1.600 g i.a. ha ${ }^{-1}$ ), diclosulam $\left(96,6\right.$; 193,17 e 386,34 g i.a. ha $\left.{ }^{-1}\right)$, imazapic (266 g i.a. ha $\left.{ }^{-1}\right)$ e imazapyr (500 e 1.000 g e.a. ha ${ }^{-1}$ ) causaram menor área foliar do perfilho principal. Todavia, para área foliar dos outros perfilhos, os menores valores foram verificados para diclosulam $\left(96,6 ; 193,17\right.$ e 386,34 g i.a. ha $\left.{ }^{-1}\right)$ e imazapyr (500 e 1.000 g e.a. ha ${ }^{-1}$ ) (Tabela 5).

Os herbicidas sulfentrazone (1.600 g i.a. ha-1), diclosulam $\left(96,6 ; 193,17\right.$ e 386,34 g i.a. ha $\left.{ }^{-1}\right)$, imazapic $\left(266\right.$ g i.a. ha $\left.{ }^{-1}\right)$ e imazapyr $(250,500$ e 1.000 g e.a. ha-1) causaram as menores massas secas da parte aérea (Tabela 6).

Beluci et al. (2015) estudaram o plantio de MPB's da variedade IACSP95-5000 aos 20, 40 e 60 DAA de herbicidas em pré-emergência. Os sintomas de injúrias foram observados aos 20 DAA quando se utilizou o imazapyr (500 g i.a. ha-1) $(26,25 \%)$, com 
Tabela 4. Clorofila a, clorofila b e clorofila total de MPB's de cana-de-açúcar, variedade RB985476, aos 30 e 60 DAA dos tratamentos em pré-plantio.

\begin{tabular}{|c|c|c|c|c|c|c|c|c|c|c|}
\hline \multirow{3}{*}{$\begin{array}{c}\text { Tratamentos } \\
\text { testemunha }\end{array}$} & \multirow{3}{*}{$\frac{\text { Doses }^{1}}{-}$} & \multicolumn{3}{|c|}{ Clorofila a } & \multicolumn{3}{|c|}{ Clorofila b } & \multicolumn{3}{|c|}{ Clorofila total } \\
\hline & & \multirow{2}{*}{$\begin{array}{c}\mathbf{3 0}^{\text {ns }} \\
31,17\end{array}$} & \multicolumn{2}{|c|}{$60 *$} & \multirow{2}{*}{$\begin{array}{c}\mathbf{3 0}^{\mathbf{n s}} \\
7,92\end{array}$} & \multicolumn{2}{|c|}{$60 *$} & \multirow{2}{*}{$\begin{array}{c}\mathbf{3 0}^{\text {ns }} \\
39,10\end{array}$} & \multicolumn{2}{|c|}{$60 *$} \\
\hline & & & 33,30 & $\mathrm{a}$ & & 12,07 & $\mathrm{a}$ & & 45,37 & $\mathrm{a}$ \\
\hline sulfentrazone & 400 & 27,02 & 31,45 & $a b$ & 7,62 & 10,02 & $a b$ & 34,65 & 41,47 & $\mathrm{ab}$ \\
\hline sulfentrazone & 800 & 26,67 & 33,02 & $\mathrm{a}$ & 6,15 & 11,05 & $a b$ & 32,82 & 44,07 & $\mathrm{a}$ \\
\hline sulfentrazone & 1.600 & 26,17 & 29,62 & $a b c$ & 6,92 & 9,52 & $a b$ & 33,10 & 39,15 & $a b c$ \\
\hline diclosulam & 96,60 & 25,62 & 29,52 & $a b c$ & 6,40 & 9,82 & $a b$ & 32,02 & 39,35 & $a b c$ \\
\hline diclosulam & 193,17 & 25,35 & 23,70 & $\mathrm{bc}$ & 5,60 & 5,70 & bc & 30,95 & 29,40 & $\mathrm{bc}$ \\
\hline diclosulam & 386,34 & 29,17 & 21,97 & $\mathrm{c}$ & 6,25 & 4,00 & $\mathrm{c}$ & 35,42 & 25,97 & $\mathrm{c}$ \\
\hline imazapic & 66,50 & 31,42 & 30,07 & $\mathrm{abc}$ & 9,50 & 9,62 & $a b$ & 40,92 & 39,70 & $a b c$ \\
\hline imazapic & 133 & 30,42 & 33,77 & $\mathrm{a}$ & 9,47 & 11,05 & $a b$ & 39,90 & 44,82 & $\mathrm{a}$ \\
\hline imazapic & 266 & 29,05 & 32,07 & $a b$ & 7,17 & 10,20 & $\mathrm{ab}$ & 36,22 & 42,27 & $\mathrm{ab}$ \\
\hline imazapyr & 250 & 29,35 & 31,07 & $\mathrm{ab}$ & 7,00 & 9,67 & $a b$ & 36,35 & 40,75 & $\mathrm{ab}$ \\
\hline imazapyr & 500 & 24,95 & 26,30 & abc & 5,62 & 7,50 & abc & 30,57 & 33,80 & abc \\
\hline \multirow[t]{4}{*}{ imazapyr } & 1.000 & 26,90 & 23,55 & $\mathrm{bc}$ & 7,12 & 6,05 & bc & 34,02 & 29,60 & bc \\
\hline & Média & 27,94 & 29,18 & & 7,13 & 8,94 & & 35,08 & 38,13 & \\
\hline & DMS & 8,44 & 8,92 & & 4,82 & 5,49 & & 11,76 & 14,05 & \\
\hline & C.V. $(\%)$ & 12,12 & 12,27 & & 27,13 & 24,64 & & 13,46 & 14,79 & \\
\hline
\end{tabular}

${ }^{1}$ Dose em g i.a. ha ${ }^{-1}$ ou g e.a. ha ${ }^{-1}$; *médias seguidas por letras iguais na coluna, não diferem entre si pelo teste Tukey a $5 \%$ de probabilidade; ${ }^{\text {ns }}=$ não significativo; DMS = diferença mínima significativa; C.V. = coeficiente de variação.

Tabela 5. Área foliar e massa seca da parte aérea (MSPA) de MPB's de cana-de-açúcar, variedade RB985476, aos 60 DAA dos tratamentos em pré-plantio.

\begin{tabular}{|c|c|c|c|c|c|c|c|}
\hline \multirow{3}{*}{$\begin{array}{l}\text { Tratamentos } \\
\text { testemunha }\end{array}$} & \multirow{3}{*}{$\begin{array}{c}\text { Doses }^{1} \\
-\end{array}$} & \multicolumn{4}{|c|}{ Área foliar $\left(\mathrm{cm}^{2}\right)$} & \multirow{2}{*}{\multicolumn{2}{|c|}{$\operatorname{MSPA}(\mathrm{g}) *$}} \\
\hline & & \multicolumn{2}{|c|}{ Perfilho principal* } & \multicolumn{2}{|c|}{ Perfilhos* } & & \\
\hline & & $1.005,84$ & $\mathrm{a}$ & 204,40 & $\mathrm{a}$ & 18,26 & $\mathrm{a}$ \\
\hline sulfentrazone & 400 & 667,24 & abcd & 117,33 & abcd & 12,40 & $a b c$ \\
\hline sulfentrazone & 800 & 798,61 & $a b c$ & 174,31 & $a b c$ & 14,24 & $a b$ \\
\hline sulfentrazone & 1.600 & 346,38 & $d$ & 176,63 & $a b$ & 9,16 & $\mathrm{bc}$ \\
\hline diclosulam & 96,60 & 414,30 & bcd & 31,04 & bcd & 7,77 & $\mathrm{bc}$ \\
\hline diclosulam & 193,17 & 367,43 & $d$ & 18,81 & bcd & 7,03 & $\mathrm{c}$ \\
\hline diclosulam & 386,34 & 370,59 & $\mathrm{~cd}$ & 4,93 & $\mathrm{~cd}$ & 6,45 & $\mathrm{c}$ \\
\hline imazapic & 66,50 & 828,25 & $\mathrm{ab}$ & 92,14 & abcd & 13,23 & $a b c$ \\
\hline imazapic & 133 & 816,51 & $a b$ & 59,27 & abcd & 12,85 & $a b c$ \\
\hline imazapic & 266 & 566,84 & bcd & 67,45 & abcd & 9,57 & $\mathrm{bc}$ \\
\hline imazapyr & 250 & 642,09 & abcd & 52,95 & abcd & 11,37 & $\mathrm{bc}$ \\
\hline imazapyr & 500 & 403,08 & bcd & 6,53 & $\mathrm{~cd}$ & 7,57 & $\mathrm{bc}$ \\
\hline \multirow[t]{4}{*}{ imazapyr } & 1.000 & 356,38 & $d$ & 1,43 & d & 6,80 & $\mathrm{c}$ \\
\hline & Média & 583,37 & & 77,48 & & 10,51 & \\
\hline & DMS & 428,78 & & 169,29 & & 6,80 & \\
\hline & C.V. (\%) & 29,49 & & 53,47 & & 25,97 & \\
\hline
\end{tabular}

${ }^{1}$ Dose em g i.a. ha ${ }^{-1}$ ou g e.a. ha ${ }^{-1} ;{ }^{*}$ médias seguidas por letras iguais na coluna, não diferem entre si pelo teste Tukey a 5\% de probabilidade; DMS = diferença mínima significativa; C.V. = coeficiente de variação; dados de área foliar de perfilhos transformados em $(\mathrm{X}+1)^{\wedge} 0,5$. 
Tabela 6. Notas de injúrias em MPB's de cana-de-açúcar, variedade RB985476, aos 7,15,30. 45 e 60 DAA dos tratamentos em pós-plantio.

\begin{tabular}{|c|c|c|c|c|c|c|c|c|}
\hline \multirow{2}{*}{ Tratamentos } & \multirow{2}{*}{ Doses $^{1}$} & \multicolumn{7}{|c|}{ Notas de injúrias (\%) } \\
\hline & & \multicolumn{2}{|c|}{$7 *$} & \multicolumn{2}{|c|}{$15^{*}$} & \multirow{2}{*}{$\begin{array}{c}\frac{\text { jurias }}{\mathbf{3 0}^{\text {ns }}} \\
0,00\end{array}$} & \multirow{2}{*}{$\begin{array}{l}\mathbf{4 5}^{\mathrm{ns}} \\
0,00\end{array}$} & \multirow{2}{*}{$\begin{array}{c}\mathbf{6 0}^{\text {ns }} \\
0,00\end{array}$} \\
\hline testemunha & - & 0,00 & $\mathrm{a}$ & 0,00 & $\mathrm{a}$ & & & \\
\hline halosulfuron & 56,25 & 0,00 & $\mathrm{a}$ & 0,00 & $\mathrm{a}$ & 1,25 & 1,75 & 2,50 \\
\hline halosulfuron & 112,50 & 0,00 & $\mathrm{a}$ & 0,75 & $\mathrm{ab}$ & 0,00 & 0,00 & 0,75 \\
\hline halosulfuron & 225 & 2,50 & $a b$ & 0,00 & $\mathrm{a}$ & 3,50 & 2,50 & 3,75 \\
\hline MSMA & 987,50 & 5,00 & $\mathrm{bc}$ & 3,00 & $\mathrm{c}$ & 3,00 & 0,75 & 0,00 \\
\hline MSMA & 1.975 & 7,25 & $\mathrm{c}$ & 6,00 & $\mathrm{~d}$ & 5,50 & 0,75 & 0,75 \\
\hline MSMA & 3.950 & 11,25 & $\mathrm{~d}$ & 10,00 & $\mathrm{e}$ & 7,25 & 1,75 & 1,25 \\
\hline ethoxysulfuron & 67,50 & 0,00 & $\mathrm{a}$ & 0,00 & $\mathrm{a}$ & 0,75 & 1,25 & 2,50 \\
\hline ethoxysulfuron & 135 & 0,75 & a & 0,75 & $\mathrm{ab}$ & 0,00 & 1,25 & 0,00 \\
\hline ethoxysulfuron & 270 & 0,00 & $\mathrm{a}$ & 2,25 & $\mathrm{bc}$ & 5,00 & 0,00 & 4,50 \\
\hline $2,4-\mathrm{D}$ & 670 & 0,75 & $\mathrm{a}$ & 0,00 & $\mathrm{a}$ & 0,00 & 0,00 & 0,00 \\
\hline $2,4-\mathrm{D}$ & 1.340 & 0,00 & a & 3,00 & $\mathrm{c}$ & 0,00 & 0,00 & 0,00 \\
\hline \multirow[t]{4}{*}{ 2,4-D } & 2.680 & 2,75 & $a b$ & 3,50 & $\mathrm{c}$ & 7,50 & 0,00 & 0,00 \\
\hline & Média & 2,32 & & 2,25 & & 2,59 & 1,15 & 1,23 \\
\hline & DMS & 3,63 & & 2,08 & & 11,74 & 6,99 & 8,96 \\
\hline & C.V. $(\%)$ & 23,29 & & 15,58 & & 51,12 & 52,14 & 60,65 \\
\hline
\end{tabular}

${ }^{1}$ Dose em g i.a. ha ${ }^{-1}$ ou g e.a. ha ${ }^{-1} ;{ }^{*}$ médias seguidas por letras iguais na coluna, não diferem entre si pelo teste Tukey a $5 \%$ de probabilidade; ${ }^{\text {ns }}=$ não significativo; DMS = diferença mínima significativa; C.V. = coeficiente de variação; dados transformados em $(\mathrm{X}+1)^{\wedge} 0,5$.

redução para 9,75\% quando o plantio foi realizado aos 40 DAA, igualando-se a testemunha aos 60 DAA. Enquanto que, imazapic (245 g i.a. ha $\left.{ }^{-1}\right)$, diclosulam + s-metolaclor $\left(88,2+1.920\right.$ gi.a. ha $\left.{ }^{-1}\right)$ e trifluralin + pendimethalin $\left(2.250+1.750 \mathrm{~g}\right.$ i.a. $\left.\mathrm{ha}^{-1}\right)$ proporcionaram sintomas de $10,0 \%$ quando utilizados aos 20 DAA. Entretanto, quando o plantio ocorreu aos 60 DAA, não foram observados sintomas de injúrias, além disso, em nenhum dos períodos de plantio foi verificado redução da altura de plantas e do teor de clorofila. $\mathrm{O}$ que difere em relação a este trabalho quanto a clorofila, na qual houve redução para os tratamentos diclosulam (D e 2D) e imazapyr (2D), além de menor altura observada para sulfentrazone (2D), diclosulam (1/2D, D e 2D) e imazapyr (D e 2D).

Dias et al. (2017) estudaram a seletividade de herbicidas em pré-plantio de MPB's das variedades CTC14, CTC7 e RB966928, usando: s-metalochlor, clomazone, sulfentrazone, diclosulam, metribuzin, diuron + hexazinone e s-metolachlor + sulfentrazone. Analisando o herbicida sulfentrazone
(800 g i.a. ha $\left.{ }^{-1}\right)$, os maiores sintomas de injúrias foram observados aos 28 DAA com 30,0 (CTC14), 26,5 (CTC7) e 20,0\% (RB966928). Entretanto, a altura, o número de perfilhos e massa seca da parte aérea foram iguais à testemunha, quanto utilizado o sulfentrazone. Apenas a massa seca de raiz foi menor quando comparada a testemunha sem aplicação, o que não foi verificado no presente trabalho, na qual a massa seca de raiz foi igual à testemunha.

A análise de variância para o experimento de pós-plantio foi significativa para sintomas de injúrias aos 7 e 15 DAA. Aos 7 DAA apenas os tratamentos que receberam MSMA resultaram em sintomas de injúrias, com notas de 5,0\% (1/2 D), $7,25 \%$ (D) e $11,0 \%$ (2D) (Tabela 6). Os sintomas apareceram primeiramente nas bordas das folhas, com manchas cloróticas que evoluíram rapidamente para necroses.

Aos 15 DAA, os mesmos tratamentos continuavam com sintomas de injúrias, mas com redução nas notas para 3,0\%,6,0\% e 10,0\% para meia dose, dose 
comercial e duas vezes a dose, respectivamente. Nesta avaliação, o herbicida ethoxysulfuron também resultou em sintomas de injúrias quando aplicado na dose de $450 \mathrm{~g}$ i.a. ha ${ }^{-1}(2,25 \%)$. Foram observados sintomas leves para o 2,4-D, nas doses de 2,0 (3,0\%) e 4,0 (6,0\%) g e.a. ha-1 (Tabela 6).

A análise de variância não foi significativa para as variáveis altura, diâmetro, número de folhas, números de perfilhos, clorofila a, clorofila b, clorofila total, área foliar e massa seca da parte aérea para os tratamentos aplicados em pós-plantio (dados não apresentados). A massa seca de raiz não foi diferente entre os tratamentos, tanto nas aplicações de pré como nas de pós-plantio (Tabela 7).

Durigan et al. (2004) estudaram a aplicação em pós-emergência da cana (40,0 a 50,0 cm de altura) dos herbicidas halosulfuron (112,5 g i.a. ha $\left.{ }^{-1}\right)$, $\operatorname{MSMA}(2.400$ g i.a. ha-1), 2,4-D (1.675 g e.a. ha-1) e trifloxysulfuron + ametryn (1.312,5 e 1.500 g i.a. ha $\left.{ }^{-1}\right)$, e verificaram que os herbicidas foram seletivos a variedade testada aos 30 e 60 dias após a aplicação
(DAA). Aos 10 DAA, o MSMA proporcionou manchas necróticas, assim como no presente trabalho, no qual foram observados os mesmos sintomas nas bordas das folhas de cana-de-açúcar. Os herbicidas 2,4-D e MSMA reduziram a altura de plantas, sendo iguais estatisticamente a testemunha não capinada. Os tratamentos com trifloxysulfuron + ametryn (1.500 g i.a. ha $\left.{ }^{-1}\right)$, MSMA e 2,4-D proporcionaram menores produtividades em relação à testemunha capinada. $\mathrm{O}$ que não foi observado neste trabalho, no qual a altura de plantas foi igual à testemunha sem aplicação.

O uso de MSMA em aplicação sequencial (área total e jato dirigido) e MSMA em única aplicação em área total, causaram sintomas de injúrias na cana-de-açúcar da variedade SP 71-1406 aos 15 DAT. Os sintomas observados foram manchas cloróticas nas regiões onde o herbicida entrou em contato com as folhas, com as maiores notas de injúrias ocorrendo nos tratamentos que utilizaram doses iguais ou superiores a $1,68 \mathrm{~kg}$ i.a. ha ${ }^{-1}$, porém as plantas se recuperam e na avaliação de 60 DAT

Tabela 7. Massa seca de raiz de MPB's de cana-de-açúcar, variedade RB985476, aos 60 DAA dos tratamentos em pré e pós-plantio.

\begin{tabular}{|c|c|c|c|c|c|}
\hline \multicolumn{3}{|c|}{ Pré-plantio } & \multicolumn{3}{|c|}{ Pós-plantio } \\
\hline Tratamentos & Doses & Massa Seca $^{\text {ns }}$ & Tratamentos & Doses & Massa Seca $^{\mathrm{ns}}$ \\
\hline testemunha & - & 2,23 & testemunha & - & 1,76 \\
\hline sulfentrazone & 400 & 2,41 & halosulfuron & 56,25 & 1,46 \\
\hline sulfentrazone & 800 & 2,49 & halosulfuron & 112,50 & 1,42 \\
\hline sulfentrazone & 1.600 & 1,64 & halosulfuron & 225 & 2,42 \\
\hline diclosulam & 96,60 & 1,19 & MSMA & 987,50 & 2,30 \\
\hline diclosulam & 193,17 & 1,02 & MSMA & 1.975 & 0,98 \\
\hline diclosulam & 386,34 & 1,37 & MSMA & 3.950 & 1,60 \\
\hline imazapic & 66,50 & 2,24 & ethoxysulfuron & 67,50 & 1,80 \\
\hline imazapic & 133 & 2,21 & ethoxysulfuron & 135 & 2,35 \\
\hline imazapic & 266 & 1,60 & ethoxysulfuron & 270 & 1,65 \\
\hline imazapyr & 250 & 2,27 & $2,4-\mathrm{D}$ & 670 & 1,99 \\
\hline imazapyr & 500 & 1,34 & $2,4-\mathrm{D}$ & 1.340 & 1,95 \\
\hline \multirow[t]{4}{*}{ imazapyr } & 1.000 & 0,92 & $2,4-\mathrm{D}$ & 2.680 & 1,52 \\
\hline & Média & 1,76 & & & 1,78 \\
\hline & DMS & 1,58 & & & 2,23 \\
\hline & C.V. $(\%)$ & 11,09 & & (\%) & 15,17 \\
\hline
\end{tabular}

Dose em g i.a. ha ${ }^{-1}$ ou g e.a. ha $^{-1}$; ns = não significativo; DMS = diferença mínima significativa; C.V. = coeficiente de variação; dados transformados em $(\mathrm{X}+1)^{\wedge} 0,5$. 
não havia mais injúrias (Foloni et al., 2008). O uso de MSMA no presente trabalho também provocou manchas cloróticas com posterior evolução para necroses nas folhas, mas aos 60 DAA os sintomas não eram mais observados.

A aplicação de imazapic (147 g i.a. ha ${ }^{-1}$ ), em pós-emergência inicial, reduziu a massa fresca e altura das variedades SP83-2847, SP87-344, SP87-396, SP89-1115 e SP90-3414. Enquanto que a aplicação de MSMA (1.920 g e.a. ha-1) reduziu massa fresca da SP80-1842, SP80-3280 e SP87-344, e altura das variedades SP80-1842, SP80-3280, SP83-2847, SP87-344, SP87-396 e SP90-3414. Já a aplicação de 2,4-D (1.005 g e.a. ha-1), reduziu altura das variedades SP80-1842, SP83-2847, SP87-344, SP87-396 e SP90-3414. Verifica-se assim, que as variedades de cana-de-açúcar possuem tolerância diferencial aos herbicidas utilizados na cultura, e dentre as quais a CTC2 e a SP80-3280 foram consideradas as mais tolerantes (Ferreira et al., 2010).

Garcia (2016) estudou a seletividade dos tratamentos herbicidas oxyfluorfen + sulfentrazone $\left(600+750 \mathrm{~g}\right.$ i.a. ha $\left.{ }^{-1}\right)$, oxyfluorfen + atrazine $\left(720+2.500\right.$ g i.a. ha $\left.{ }^{-1}\right)$, tebuthiuron + sulfentrazone $\left(1.100+750\right.$ g i.a. ha $\left.{ }^{-1}\right)$, s-metolaclor + sulfentrazone $\left(2.112+750\right.$ gi.a. ha $\left.{ }^{-1}\right)$, clomazone + atrazine $\left(1.008+2.500 \mathrm{~g}\right.$ i.a. ha $\left.{ }^{-1}\right)$, clomazone + sulfentrazone $\left(1.080+750\right.$ g i.a. ha $\left.{ }^{-1}\right)$, mais uma testemunha capinada, em pós-emergência de MPB's, variedade CTC 14. Aos 15 DAP todos os tratamentos resultaram em injúrias, aos 78 DAP apenas oxyfluorfen + sulfentrazone e tebuthiuron + sulfentrazone apresentavam sintomas, com 5,0\% e $6,25 \%$, respectivamente. As variáveis altura e diâmetro foram iguais estatisticamente entre todos os tratamentos, em todas as avaliações, assim como a produtividade, concluindo que todos os herbicidas foram seletivos as MPB's quando aplicados em pré-plantio. $\mathrm{O}$ que difere dos resultados encontrados neste trabalho, no qual houve redução de altura para alguns tratamentos em pré-plantio, porém na variedade RB985476.
Os resultados da presente pesquisa demonstraram que a seletividade de herbicidas em mudas pré-brotadas de cana-de-açúcar vai depender do momento de aplicação e de como ele é posicionado (pré ou pós-plantio). Mais estudos são necessários para esclarecer se a seletividade será verificada na colheita e se os resultados podem ser extrapolados para outras variedades.

\section{Conclusão}

Os herbicidas aplicados em pós-plantio (halosulfuron, ethoxysulfuron, 2,4-D e MSMA) não alteraram o crescimento inicial da variedade RB985476. Para os herbicidas em pré-plantio (sulfentrazone, diclosulam, imazapic e imazapyr), o sulfentrazone proporcionou os maiores sintomas de injúrias, sendo necessários mais estudos para posicionar corretamente os produtos antes do plantio das MPB's.

\section{Referências}

Barbieri Junior, É.; Rossiello, R.O.P.; Silva, R.V.M.M.; Ribeiro, R.C.; Morenz, M.J.F. Um novo clorofilômetro para estimar os teores de clorofila em folhas do capim Tifton 85. Ciência Rural, v.42, n.12, p.2242-2245, 2012. http:// dx.doi.org/10.1590/S0103-84782012005000109.

Beluci, L.R.; Vitorino, R.; Azania, C.A.M.; Azania, A.D.P.A.M.; Tortorelli, H.F. Utilização do perfil isoenzimático como ferramenta na avaliação da seletividade de herbicidas em cana-de-açúcar. Nucleus, v.12, n.2, p.157-166, 2015. http://dx.doi. org/10.3738/1982.2278.1436.

CONAB - Companhia Nacional de Abastecimento. Acompanhamento da safra brasileira: cana-deaçúcar: safra 2016/2017, quarto levantamento, abril de 2017. Brasília: CONAB, 2017. 82p.

Dias, J.L.C.D.S.; Silva Junior, A.C.D.; Queiroz, J.R.G.; Martins, D. Herbicides selectivity in pre-budded seedlings of sugarcane. Arquivos do Instituto Biológico, v.84, p.1-9, 2017. http:// dx.doi.org/10.1590/1808-1657000112015. 
Durigan, J.C.; Timossi, P.C.; Correia, N.M. Densidades e manejo químico da tiririca na produtividade de cana-de-açúcar. Planta Daninha, v.23, n.3, p.463-469, 2005. http://dx.doi.org/10.1590/ S0100-83582005000300010.

Durigan, J.C.; Timossi, P.C.; Leite, G.J. Controle químico da tiririca (Cyperus rotundus), com e sem cobertura do solo pela palha de cana-de-açúcar. Planta Daninha, v.22, n.1, p.127-135, 2004. http:// dx.doi.org/10.1590/S0100-83582004000100016.

EWRC - European Weed Research Council. Report of the 3rd and 4rd meetings of EWRC Committee of methods in weed research. Weed Research, v.4, n.1, p.88, 1964.

Ferreira, R.R.; Oliveira, F.T.R.; Delite, F.S.; Azevedo, R.A.; Nicolai, M.; Carvalho, S.J.P.; et al. Tolerância diferencial de variedades de cana-deaçúcar a estresse por herbicidas. Bragantia, v.69, n.2, p.395-404, 2010. http://dx.doi.org/10.1590/ S0006-87052010000200019.

Foloni, L.L.; Christoffoleti, P.J.; Carvalho, S.J.P.; Nicolai, M. Purple nutsedge (Cyperus rotundus) management program in sugarcane crop with isolated or sequential application of MSMA. Planta Daninha, v.26, n.4, p.883-892, 2008. http:// dx.doi.org/10.1590/S0100-83582008000400020.

Garcia, M.P. Seletividade de tratamentos herbicidas em mudas pré-brotadas de cana-deaçúcar CTC14. 2016. 57 f. Dissertação (Mestrado em Agronomia) - Faculdade de Ciências Agrárias e Veterinárias, Universidade Estadual Paulista "Júlio de Mesquita Filho", Jaboticabal, 2016.

Giraldeli, A.L.; Monquero, P.A.; Malardo, M.R.; Ramos, S.K.; Torres, B.A.; Gomes, R.R.; Silva, P.V. Interação entre herbicidas e nematicidas na cultura da cana-de-açúcar. Revista Brasileira de Herbicidas, v.15, n.4, p.341-352, 2016. http:// dx.doi.org/10.7824/rbh.v15i4.462.

Gírio, L.A.S.; Dias, F.L.F.; Reis, V.M.; Urquiaga, S.; Schultz, N.; Bolonhezi, D.; Mutton, M.A. Bactérias promotoras de crescimento e adubação nitrogenada no crescimento inicial de canade-açúcar proveniente de mudas pré-brotadas. Pesquisa Agropecuária Brasileira, v.50, n.1, p.33-43, 2015. http://dx.doi.org/10.1590/S0100204X2015000100004.

Kuva, M.A.; Pitelli, R.A.; Alves, P.L.C.A.; Salgado, T.P.; Pavani, M.C.D.M. Banco de sementes de plantas daninhas e sua correlação com a flora estabelecida no agroecossistema cana-crua. Planta Daninha, v.26, n.4, p.735-744, 2008. http://dx.doi. org/10.1590/S0100-83582008000400004.

Kuva, M.A.; Pitelli, R.A.; Christoffoleti, P.J.; Alves, P.L.C.A. Períodos de interferência das plantas daninhas na cultura da cana-de-açúcar. I - tiririca. Planta Daninha, v.18, n.2, p.241251, 2000. http://dx.doi.org/10.1590/S010083582000000200006 .

Kuva, M.A.; Pitelli, R.A.; Salgado, T.P.; Alves, P.L.C.A. Fitossociologia de comunidades de plantas daninhas em agroecossistema cana-crua. Planta Daninha, v.25, n.3, p.501-511, 2007. http:// dx.doi.org/10.1590/S0100-83582007000300009.

Landell, M.D.A.; Campana, M.P.; Figueiredo, P.; Xavier, M.A.; Anjos, I.A.; Dinardo-Miranda, L.L.; et al. Sistema de multiplicação de canade-açúcar com uso de mudas pré-brotadas (MPB), oriundas de gemas individualizadas. Ribeirão Preto: Instituto Agronômico de Campinas, 2012. 22p.

Pimentel-Gomes, F.; Garcia, C.H. Estatística aplicada a experimentos agronômicos e florestais: exposição com exemplos e orientações para uso de aplicativos. Piracicaba: FEALQ, 2002. 309p.

RIDESA - Rede Interuniversitária para o Desenvolvimento do Setor Sucroenergético. 45 anos de variedades RB de cana-de-açúcar: 25 anos de Ridesa. Curitiba: Graciosa, 2015. 159p.

Rodrigues, B.N.; Almeida, F.S. Guia de herbicidas. Londrina: Edição dos Autores, 2011. 697p.

Sabbag, R.S.; Monquero, P.A.; Hirata, A.C.S.; Santos, P.H.V. Crescimento inicial de mudas 
pré brotadas de cana-de-açúcar submetidas a aplicação de herbicidas. Revista Brasileira de Herbicidas, v.16, n.1, p.38-49, 2017. http://dx.doi. org/10.7824/rbh.v16i1.481.

Silva, G.S.; Silva, A.F.M.; Giraldeli, A.L.; Ghirardello, G.A.; Victoria Filho, R.; Toledo, R.E.B. Manejo de plantas daninhas no sistema de mudas pré-brotadas de cana-de-açúcar. Revista Brasileira de Herbicidas, v.17, n.1, p.86-94, 2018. http://dx.doi.org/10.7824/rbh.v1i1.526.
Velini, D.E.; Osipe, R.; Gazziero, D.L.P. Procedimentos para instalação, avaliação e análise de experimentos com herbicidas. Londrina: SBCPD, 1995. 42p.

Xavier, M.A.; Landell, M.G.A.; Teixeira, L.G.; Rodrigues, P.A.; Nassif, G.L.; Oliveira Junior, A.C.; Mine, K. Sistema de multiplicação MPB e integração com o setor sucroenergético. $\mathbf{O}$ Agronômico, v.64-66, p.32-41, 2014. 